\title{
Does Information Transparency Decrease Coordination Failure?
}

\author{
Regina M. Anctil \\ University of St. Thomas, Minneapolis, MN \\ John Dickhaut \\ University of Minnesota \\ Cathleen Johnson \\ University of Arizona \\ Chandra Kanodia \\ University of Minnesota
}

October 2008

The authors thank Frederick Rankin, Orly Sade, Jason Kuang, and participants at the 2004 American Economics Association annual meetings for discussions that lead to this study. We also acknowledge the comments and suggestions of Andreas Blume, Rene Garcia, Kevin McCabe, Dave Porter, and participants at workshops at the University of St. Thomas, University of Minnesota, George Mason University, Center for Interuniversity Research and Analysis on Organizations, Montreal, QC, and the 2004 Economic Science Association North American Regional Meetings. 


\title{
Does Information Transparency Decrease Coordination Failure?
}

\begin{abstract}
This study experimentally tests the effect of information transparency on the probability of coordination failure in global games with finite signals. Prior theory has shown that in global games with unique equilibrium, the effect of information transparency is ambiguous. We find that in global games where the signal space is finite, increased transparency has two effects. First, increasing the level of transparency usually destroys uniqueness and precipitates multiple equilibria, so that the effect of transparency on coordination depends crucially upon which equilibrium is actually attained. Second, the level of transparency determines which of these equilibria is risk dominant. We find that increased transparency facilitates coordination only if it switches the risk-dominant equilibrium from the secure equilibrium to the efficient equilibrium. When the converse is true, improved transparency can be dysfunctional because it increases the probability of coordination failure.
\end{abstract}




\section{Information Transparency and Coordination Failure: Efficiency, Security, and Risk Dominance}

\section{Introduction}

Economic settings with strategic complementarities and complete information are usually plagued by multiple equilibria. There is an efficient, Pareto superior, equilibrium and an inferior, but secure, equilibrium. The multiplicity of equilibria creates strategic uncertainty, in that each individual player is unsure which equilibrium others are playing. Coordination failure occurs when players are unable to coordinate their actions to attain the Pareto superior equilibrium. Diamond and Dybvig (1983) argue that bank runs are a consequence of such coordination failures. But, the harmful effects of coordination failure are not confined to macro-economic phenomena. It is also a pervasive management problem. Consider the case of a firm undertaking a strategic initiative to improve, say, customer satisfaction. Successful implementation of the program depends on the actions of individuals and departments at every level of the organization. Each manager must decide whether to commit scarce resources to the program. Even a small loss of confidence that others will stay the course to achieve the Pareto superior equilibrium can lead to the individual defection of every agent, resulting in coordination failure. Thus a promising initiative could fail.

Cooper, DeJong, Forsythe, and Ross (1990) provide experimental evidence that even in simple two-person coordination games with complete information, the Pareto superior equilibrium is not guaranteed. Van Huyck, Battalio and Beil (1990) found that when the number of players is large coordination failure is almost certain to occur. In another experiment, Van Huyck, Battalio, and Beil (1991) examine equilibrium selection in an average opinion game with secure and efficient equilibria. They find that subjects converge to the efficient equilibrium only when the secure equilibrium is rendered non-salient, and vice versa. When both strategies are salient, neither equilibrium is supported. 
Carlsson and Van Damme (1993) argued that the multiplicity of equilibria in coordination games is an artifact of the assumption that the payoff structure of every player is common knowledge. They studied a global game structure, where Nature first randomly chooses the coordination game to be played from a subclass of 2 X 2 games and then each player observes a noisy, idiosyncratic, signal of the selected game. They established that in such global games the equilibrium is unique, and that as the noise in player's observations vanishes, the sequence of unique equilibria converges to the risk dominant equilibrium of the game actually selected by Nature. Thus, if games of complete information are viewed as limits of games with incomplete information, then risk dominance, as proposed by Harsanyi and Selten (1988), is a compelling equilibrium selection criterion. Global games have been used to study many macroeconomic phenomena such as currency attacks (Morris and Shin, 1998), premature foreclosure of loans (Morris and Shin, 2004) and bank runs (Goldstein and Pauzner, 2005). Morris and Shin (2003) provides an excellent overview of global game applications. The common finding in these studies is that even though the multiplicity of equilibrium problem disappears, there is still a non-empty region of fundamentals where inefficient equilibria are attained due to lack of coordination.

The motivation for our paper is twofold. First, we provide experimental evidence on whether increasing the transparency of information received by individual agents in global games increases or decreases the region of inefficiency where coordination failure occurs. The importance of this question is apparent from the empirical observation that most public incidents of coordination failure are accompanied by a clamor for increased transparency. Morris and Shin (2004) were the first to pose this problem. They established that when uniqueness of equilibrium is preserved, the effect of increased transparency is ambiguous, and there are parameter values where increased transparency of information actually increases the incidence of coordination failure. We add to the Morris and Shin result by studying settings where increasing the transparency of information destroys uniqueness and precipitates multiple equilibria. The uniqueness of equilibrium in global games depends upon smooth variation in the beliefs of individual players as signals vary. In many 
situations, especially those arising in corporate management settings, the space of fundamentals over which there is uncertainty and the set of signals from which agents draw is finite. In such finite settings, there are discrete jumps in players' beliefs and it is easy to find examples where increased transparency of information destroys uniqueness of equilibrium and precipitates multiple equilibria. In these cases, increased transparency induces an equilibrium selection problem. Therefore, the effect of increasing the transparency of information received by agents depends crucially upon which equilibrium is actually selected. Our second objective is to shed light on the equilibrium selection problem in global game settings with finite signals where multiple equilibria occur. We provide experimental evidence that players in the global game converge rapidly to the equilibrium that is risk dominant in an "otherwise identical" game where fundamental uncertainty remains but there is no uncertainty about the beliefs of other players.

Our experiments are based on the Morris and Shin (2004) model of loan foreclosure decisions. We run experiments where the multiple equilibria generated by increased transparency consists of both an efficient equilibrium and an inefficient equilibrium. In some of our treatments, increased transparency makes the efficient equilibrium risk dominant in the "otherwise identical" game, while in other treatments increased transparency makes the inefficient equilibrium risk dominant. We find that in all our treatments, subjects converge rapidly to the risk dominant equilibrium, regardless of whether it is efficient or inefficient. Thus, we conclude that increased transparency is socially desirable only when it also makes the efficient equilibrium risk dominant. In cases where the inefficient equilibrium becomes risk dominant, increased transparency is socially undesirable.

Heinemann, Nagel, and Ockenfels (2004) present related experimental evidence on the importance of risk dominance in equilibrium selection. They compare equilibria in complete information currency attack games where the state is publicly revealed, to equilibria in global games where each player receives a noisy private signal of the state. In the former setting there are multiple equilibria, while in the global game setting there is a unique equilibrium characterized by a threshold 
signal above which players attack the currency peg. Their experimental finding is that players converge to a unique threshold strategy in both settings. Moreover the threshold adopted in the public information setting is close to the unique threshold implied by vanishing signal noise in the corresponding global game. Thus players appear to coordinate on the risk dominant equilibrium in the public information game, and other equilibrium selection criteria do not have as much explanatory power. Anctil, Dickhaut, Kanodia, and Shapiro (ADKS, 2004) also examine the role of information in global games. They find that the efficient equilibrium emerges when the prior public information is sufficiently optimistic; and the secure equilibrium emerges when this information is not optimistic. They conjecture that information plays a role because it influences which equilibrium is risk dominant. The results of our study indicate that the conjecture made in ADKS is indeed correct.

The remainder of this paper is organized as follows. In Section II we provide the theory underlying our experiments. In Section III we describe our experimental design, experimental procedures and the specific parameters used in our treatments. Section IV describes our experimental results, and Section V concludes the paper.

\section{The Loan Foreclosure Game with Finite Signals}

Consider a finite number of creditors (there are eight creditors in each of our experiments) who must each independently decide whether to rollover or foreclose a loan that was earlier made to finance a risky project. There are three possible states, bankrupt (B), uncertain (U) and solvent (S). In state B the project fails regardless of what creditors do, and any creditor who rolls over her loan receives a payoff of zero. In state $\mathrm{S}$, the project succeeds regardless of creditors' actions and any creditor who rolls over her loan receives a payoff $R>0$. In state $U$, the project succeeds if and only if at least $\mathrm{z}<8$ of the 8 creditors roll over their loans, in which case creditors who roll over each receive the payoff $\mathrm{R}$. In all three states, any creditor who forecloses receives a secure payoff $\lambda$, 
$0<\lambda<\mathrm{R}$, regardless of what other creditors do. Thus, as depicted below, creditors play one of the three possible games indexed by the state. For expositional ease, we describe the payoffs for two person games - the extension to 8 player games is straight forward.

\section{Game B}

\begin{tabular}{|l|l|l|}
\hline & Rollover & Foreclose \\
\hline Rollover & 0,0 & $0, \lambda$ \\
\hline Foreclose & $\lambda, 0$ & $\lambda, \lambda$ \\
\hline
\end{tabular}

\section{Game U}

\begin{tabular}{|l|l|l|}
\hline & Rollover & Foreclose \\
\hline Rollover & $\mathrm{R}, \mathrm{R}$ & $0, \lambda$ \\
\hline Foreclose & $\lambda, 0$ & $\lambda, \lambda$ \\
\hline
\end{tabular}

\section{Game S}

\begin{tabular}{|l|l|l|}
\hline & Rollover & Foreclose \\
\hline Rollover & $\mathrm{R}, \mathrm{R}$ & $\mathrm{R}, \lambda$ \\
\hline Foreclose & $\lambda, \mathrm{R}$ & $\lambda, \lambda$ \\
\hline
\end{tabular}

Since foreclose is a dominant action in Game B and rollover is a dominant action in Game $\mathrm{S}$, the Nash equilibrium is unique in these games. However Game U has two Nash equilibria, \{rollover, rollover $\}$ and \{foreclose,foreclose , with the former being Pareto superior. If Game U is being played and the $\{$ foreclose, foreclose $\}$ equilibrium is attained, there is coordination failure.

However, players do not know which of the three games is being played. Nature makes this choice with probabilities $\pi_{B}, \pi_{U}, \pi_{S}$, respectively. Each player independently receives one of three signals, $l, m$, or $h$ that is informative about Nature's choice. The conditional probabilities of these signals are described in Table 1 below: 


\section{Table 1}

\section{STATES}

$\begin{array}{ccccc} & & \mathrm{B} & \mathrm{U} & \mathrm{S} \\ & l & r_{B} & 0 & 0 \\ \text { SIGNALS } & m & 1-r_{B} & 1 & 1-r_{S} \\ & h & 0 & 0 & r_{S}\end{array}$

Given the conditional probabilities in Table I, any player receiving signal $l$ knows for certain that state B has occurred, but cannot rule out the possibility that some of the other players have received signal $m$. Similarly, any player receiving signal $h$ knows for certain that state $\mathrm{S}$ has occurred, but cannot rule the possibility that some of the other players have received signal $\mathrm{m}$. Signal $\mathrm{m}$ communicates noisy information about the state, and any player receiving signal $m$ cannot rule out the possibility that the other players may have received any of the three signals $l, m$ or $h$. Thus, players receiving either signal $l$ or $h$ have no fundamental uncertainty, but do face strategic uncertainty, while players receiving signal $m$ face both fundamental and strategic uncertainty. We chose this probability structure to keep the global game simple and to facilitate the manipulation of information transparency.

We restrict attention to pure strategy symmetric Nash equilibria. A pure strategy for each player is a function $\sigma($.$) specifying an action contingent on each signal. Since signal l$ communicates that state $\mathrm{B}$ has occurred for certain and since foreclose is a dominant action in state $\mathrm{B}, \sigma(l)=$ foreclose must be part of any equilibrium strategy profile. Similarly, since receipt of signal $h$ makes rollover a dominant action, $\sigma(h)=$ rollover must be part of any equilibrium strategy profile. Now, consider a creditor's problem when she observes signal $m$. Given signal $m$, each of the three states has positive probability, and the posterior probabilities, $\operatorname{Prob}(\mathrm{B} \mid m), \operatorname{Prob}(\mathrm{U} \mid m)$, and $\operatorname{Prob}(\mathrm{S} \mid m)$ can 
be calculated via Bayes theorem. Since project success is guaranteed in state S regardless of other players' actions, the action rollover is a dominant action for any player who receives signal $m$ if :

$$
\operatorname{Prob}(\mathrm{S} \mid m) \mathrm{R}>\lambda
$$

Also, since project failure is guaranteed in state B regardless of other players' actions, foreclose is a dominant action for any player who receives signal $m$ if :

$$
[\operatorname{Prob}(\mathrm{U} \mid m)+\operatorname{Prob}(\mathrm{S} \mid m)] \mathrm{R}<\lambda .
$$

If either (1) or (2) is satisfied, there is a unique equilibrium in the global game. A creditor's choice is more difficult when both (1) and (2) are violated, i.e., when:

$$
\operatorname{Prob}(S \mid m)<\frac{\lambda}{R}<[\operatorname{Prob}(U \mid m)+\operatorname{Prob}(S \mid m)]
$$

Let $\Omega$ be the non-empty set of parameters $\left\{\pi_{\mathrm{B}}, \pi_{\mathrm{U}}, \pi_{\mathrm{S}}, \mathrm{r}_{\mathrm{B}}, \mathrm{r}_{\mathrm{S}}, \lambda, \mathrm{R}\right\}$ which satisfy (3).

When (3) is satisfied, a creditor receiving signal $m$ must additionally assess the probability of project success in each of the three feasible states. Since this probability is exogenously given for states B and $\mathrm{S}$, the critical assessment is the probability of success in state $\mathrm{U}$. Because all creditors receive signal $m$ when the state is $\mathrm{U}$, a creditor's assessment of the probability of project success in state $\mathrm{U}$ is determined by her belief of what other creditors will do upon receiving signal $\mathrm{m}$. Since other creditors are thinking likewise, this assessment implicitly depends on the entire hierarchy of higher order beliefs - beliefs about other creditors' beliefs, beliefs about others' beliefs about others' beliefs and so on. If each creditor believes that others will rollover upon observing $m$ then each creditor must assess the probability of success in state $U$ to be one, and if each creditor believes that others will foreclose upon observing $m$ then each creditor must assess the probability of success in state $\mathrm{U}$ to be zero. In the former case $\sigma(m)=$ rollover is an equilibrium supported by self-fulfilling beliefs and in the latter case $\sigma(m)=$ foreclose is an equilibrium supported by self-fulfilling beliefs. Thus, in the global game, there are two equilibrium strategy profiles each supported by self-fulfilling beliefs. The equilibrium selection problem reappears. This situation is endemic in global games with a finite number of signals because there are discrete jumps in players' beliefs. 
We now define an "otherwise identical" game where the notion of risk dominance is well defined. Suppose that only one signal is drawn in accordance with the prior probabilities of the three states and the conditional probabilities described in Table I, and this signal is publicly announced. In this otherwise identical game there is no private information, only public information. Thus, when signal $m$ is drawn and publicly announced, fundamental uncertainty is still present, but there is no uncertainty about the information of other players. The game contingent on signal $m$ has common knowledge, so it is essentially a game of complete information with payoffs replaced by expected payoffs (see Hellwig, 2002). We call this game $\mathrm{PI}(m)$ and depict it below for the case of two players.

Game PI(m)

\begin{tabular}{|l|l|l|}
\hline & Rollover & Foreclose \\
\hline Rollover & {$[\operatorname{Prob}(\mathrm{S} \mid m)+\operatorname{Prob}(\mathrm{U} \mid m)] \mathrm{R},[\operatorname{Prob}(\mathrm{S} \mid m)+\operatorname{Prob}(\mathrm{U} \mid m)] \mathrm{R}$} & $\operatorname{Prob}(\mathrm{S} \mid m) \mathrm{R}, \lambda$ \\
\hline Foreclose & $\lambda, \operatorname{Prob}(\mathrm{S} \mid m) \mathrm{R}$ & $\lambda, \lambda$ \\
\hline
\end{tabular}

It should be noted that game $\operatorname{PI}(m)$ is different from the situation where a player privately observes signal $m$. In the latter case, each of the other players could have received any signal from $\{l, m\}$ or any signal from $\{h, m\}$, so there is uncertainty about other players beliefs. In game $\operatorname{PI}(m)$ there is no uncertainty about other players' beliefs.

When the inequalities in (3) are satisfied, game $\mathrm{PI}(m)$ has two equilibria, \{rollover, rollover $\}$ and \{foreclose, foreclose $\}$. The risk-dominant equilibrium is that equilibrium which has the largest product of deviation losses. So \{rollover, rollover $\}$ is risk dominant if,

$$
[\operatorname{Prob}(U \mid m)+\operatorname{Prob}(S \mid m)]-\frac{\lambda}{R}>\frac{\lambda}{R}-\operatorname{Prob}(S \mid m)
$$

and, \{foreclose, foreclose $\}$ is risk dominant if the inequality in (4) is reversed. Which of the two equilibria is efficient? Since message $m$ provides only noisy information about the state, efficiency must be assessed from an ex ante perspective. A creditor's expected payoff from the rrollover, rollover equilibrium is:

$$
\pi_{S} \operatorname{Prob}(h \mid S) R+\pi_{S} \operatorname{Prob}(m \mid S) R+\pi_{U} R+\pi_{B} \operatorname{Prob}(l \mid B) \lambda
$$


Her expected payoff from the \{foreclose, foreclose $\}$ equilibrium is:

$$
\pi_{S} \operatorname{Prob}(h \mid S) R+\pi_{S} \operatorname{Prob}(m \mid S) \lambda+\pi_{U} \lambda+\pi_{B} \operatorname{Prob}(l \mid B) \lambda+\pi_{B} \operatorname{Prob}(m \mid B) \lambda
$$

Therefore $\{$ rollover, rollover is the efficient equilibrium if

$$
\frac{\pi_{S} \operatorname{Prob}(m \mid S)+\pi_{U}}{\pi_{S} \operatorname{Prob}(m \mid S)+\pi_{U}+\pi_{B} \operatorname{Pr} o b(m \mid B)}>\frac{\lambda}{R}
$$

or, equivalently if:

$$
[\operatorname{Prob}(S \mid m)+\operatorname{Prob}(U \mid m)]>\frac{\lambda}{R}
$$

This last inequality is satisfied for every specification of parameters in the set $\Omega$. Thus, given the structure of our global game, whenever there are multiple equilibria the efficient equilibrium is \{rollover, rollover $\}$, and the inefficient equilibrium is $\{$ foreclose, foreclose $\}$. If the efficient equilibrium is achieved there is no coordination failure in state $\mathrm{U}$.

We hypothesize that whenever there are multiple equilibria in the global game, all creditors who privately observe signal $m$ will rollover when \{rollover, rollover \} is the risk dominant equilibrium in game $\mathrm{PI}(\mathrm{m})$, and will foreclose when \{foreclose, foreclose $\}$ is the risk dominant equilibrium in game $\operatorname{PI}(m)$. There are two plausible alternative hypothesis: (i) Players always coordinate on the efficient equilibrium and rollover upon seeing message $m$ and, (ii) Players always coordinate on the secure equilibrium and foreclose upon seeing message $m$.

We now show how transparency of information determines which equilibrium is risk dominant in the otherwise identical game. Given the probability specifications in Table 1, it is intuitive that any increase in either of the parameters $r_{B}, r_{S}$, or an increase in both, will increase signal transparency. This claim can be formally proved in terms of Blackwell fineness by construction of one conditional probability matrix as a stochastic transformation of the other. Now, since 


$$
\operatorname{Prob}(S \mid m)=\frac{\pi_{S}\left(1-r_{S}\right)}{\pi_{S}\left(1-r_{S}\right)+\pi_{U}+\pi_{B}\left(1-r_{B}\right)},
$$

this probability is strictly decreasing in $r_{S}$ and strictly increasing in $r_{B}$. Also since

$$
\operatorname{Prob}(S \mid m)+\operatorname{Prob}(U \mid m)=\frac{\pi_{S}\left(1-r_{S}\right)+\pi_{U}}{\pi_{S}\left(1-r_{S}\right)+\pi_{U}+\pi_{B}\left(1-r_{B}\right)},
$$

this sum of probabilities is also strictly decreasing in $r_{S}$ and strictly increasing in $r_{B}$. Therefore, an increase in the parameter $r_{S}$ decreases the left hand side and increases the right hand side of (4). Increases in the parameter $r_{B}$ have the opposite effect, increasing the left hand side and decreasing the right hand side of (4). Therefore, within the set of parameters contained in $\Omega$, an increase in transparency caused by an increase in $r_{S}$ will tend to make the \{foreclose, foreclose $\}$ equilibrium risk dominant. On the other hand, increases in transparency caused by an increase in the parameter $r_{B}$ will tend to make the rollover, rollover equilibrium risk dominant. Since the latter is always the efficient equilibrium, an increase in transparency could be socially desirable or socially undesirable depending on whether, or not, it results in the efficient equilibrium becoming risk dominant.

The above proposition depends crucially upon players choosing the predicted risk dominant equilibrium in global games with multiple equilibria, regardless of how increased transparency is attained and regardless of which equilibrium is more efficient. The experiments we describe in the rest of the paper are designed precisely to test for such behavior.

\section{Experimental Design}

\section{Treatments and Predictions}

In the experiment a creditor group consists of eight players, with $z=5$, meaning that project success in state $U$ requires at least five players to roll over. Within a treatment, we hold payoffs, $\{R$, $\lambda\}$, and public information, $\left\{\pi_{B}, \pi_{U}, \pi_{S}\right\}$, constant, and manipulate risk dominance by changing the transparency of private signals through the parameters $r_{B}$ and $r_{S}$. The transparency treatment is 
imposed on two economic parameterizations, an "Optimistic" setting represented by $\{R, \lambda\}=\{\$ 0.50$, $\$ 0.20\}$ and $\left\{\pi_{B}, \pi_{U}, \pi_{S}\right\}=\{0.3,0.2,0.5\}$, and a "Pessimistic" setting represented by $\{R, \lambda\}=\{\$ 0.50$, $\$ 0.30\}$ and $\left\{\pi_{B}, \pi_{U}, \pi_{S}\right\}=\{0.5,0.2,0.2\}$. Transparency varies from "Low," $\left\{r_{B}, r_{S}\right\}=\{0.4,0.4\}$, to "Higher," $\left\{r_{B}, r_{S}\right\}=\{0.4,0.9\}$ or $\left\{r_{B}, r_{S}\right\}=\{0.9,0.4\}$, to "Highest," $\left\{r_{B}, r_{S}\right\}=\{0.9,0.9\} .{ }^{1}$ Panels A and B of Table 2 summarize the parameters and transparency levels used in the experiment.

\section{[Table 2]}

In the Optimistic setting, as described in Panel A of Table 2, the parameter $\frac{\lambda}{R}=0.4$. With low transparency $\left(r_{B}=r_{S}=0.4\right), \operatorname{Prob}(\mathrm{S} \mid m)=0.4412>\frac{\lambda}{R}$, which, from (1), implies that rollover is a dominant action for any player who receives message $m$. With higher transparency $\left(r_{B}=0.4, r_{S}=\right.$ $0.9), \operatorname{Prob}(\mathrm{S} \mid m)=0.1163$ and $\operatorname{Prob}(\mathrm{U} \mid m)=0.4651$, which, from (3), implies that there are multiple equilibira. But, since $\operatorname{Prob}(\mathrm{U} \mid m)+\operatorname{Prob}(\mathrm{S} \mid m)-\frac{\lambda}{R}<\frac{\lambda}{R}-\operatorname{Prob}(\mathrm{S} \mid m)$, the strategy profile $\{$ foreclose, foreclose $\}$ is risk dominant as argued in (4). With highest transparency $\left(r_{B}=r_{S}=0.9\right)$, Prob(S|m)= 0.1786 and $\operatorname{Prob}(\mathrm{U} \mid m)=0.7143$, which, from (3), again implies that there are multiple equilibira. But, this time, since $\operatorname{Prob}(\mathrm{U} \mid m)+\operatorname{Prob}(\mathrm{S} \mid m)-\frac{\lambda}{R}>\frac{\lambda}{R}-\operatorname{Prob}(\mathrm{S} \mid m)$, the strategy profile \{rollover, rollover is risk dominant as argued in (4). Thus in the Optimistic setting, the equilibrium in the global game is unique and is supported by dominant strategies when transparency is low, but increasing the level of transparency precipitates multiple equilibria. Given multiple equilibria, the risk dominant strategy is inefficient with "higher transparency", but is efficient with "highest transparency."

In the Pessimistic setting, as described in Panel B of Table 2, the parameter $\frac{\lambda}{R}=0.6$. With low transparency $\left(r_{B}=r_{S}=0.4\right), \operatorname{Prob}(\mathrm{S} \mid m)=0.2647$ and $\operatorname{Prob}(\mathrm{U} \mid \mathrm{m})=0.2941$, so that their $\mathrm{sum}<$

\footnotetext{
${ }^{1}$ The labels Optimistic, Pessimistic, Low, Higher, and Highest are only used for data reporting purposes. Each subject participates in only one economic setting under one level of transparency.
} 
$\frac{\lambda}{R}$, which, from (2), implies that foreclose is a dominant action for any player who receives message $m$. With higher transparency $\left(r_{B}=0.9, r_{S}=0.4\right), \operatorname{Prob}(\mathrm{S} \mid m)=0.4186$ and $\operatorname{Prob}(\mathrm{U} \mid m)=$ 0.4651, which, from (3), implies that there are multiple equilibira, and, from (4), the strategy profile $\{$ rollover, rollover $\}$ is risk dominant. With highest transparency $\left(r_{B}=r_{S}=0.9\right), \operatorname{Prob}(\mathrm{S} \mid m)=0.1071$ and $\operatorname{Prob}(\mathrm{U} \mid m)=0.7143$, which, from (3), again implies that there are multiple equilibira, and, this time, the strategy profile $\{$ foreclose, foreclose $\}$ is risk dominant. Thus, once again as transparency is increased the equilibrium in the global game moves from a unique equilibrium supported by dominant strategies to multiple equilibria. However, in contrast to the Optimistic setting, in the Pessimistic setting the risk dominant strategy is efficient with "higher transparency", but is inefficient with "highest transparency."

Our equilibrium predictions, together with equilibrium expected payoffs and the expected losses from deviations are summarized in Panels A and B of Table 3. The strategy $\sigma(l)=$ foreclose, $\sigma(m)=$ rollover,$\sigma(h)=$ rollover, is labeled $F l$, and the strategy $\sigma(l)=$ foreclose, $\sigma(m)=$ foreclose, $\sigma(h)=$ rollover, is labeled $F m$.

\section{[Table 3]}

\section{Procedures}

All six of the experimental manipulations described above were tested at the Bell Laboratory for Experimental Economics at the Center for Interuniversity Research and Analysis on Organizations (CIRANO), in Montreal, Quebec. In total, 138 subjects participated. Prior to each session, participants completed a set of instructions provided in written and oral form, and completed interim questions and an overall questionnaire on the procedures. Each person then participated in an unspecified number of decision periods, where in each period he or she was randomly grouped with seven other participants. ${ }^{2}$ The appendix to this paper shows a copy of the instructions and

\footnotetext{
${ }^{2}$ In each decision period subjects were randomly selected to be included in eight-person groups with the remaining participants serving as alternates. Subjects were not informed about their status. Each alternate was
} 
questionnaire participants completed in the Optimistic, Low transparency cell of the experiment. Aside from differences in numerical parameters, all instructions and questionnaires used in the experiment were identical. Each session covered approximately two hours and paid participants an average of $\$ 44.58$ (CAD). The following paragraph describes the participants' information and decisions in a session.

In each session participants are publicly informed of the payoff structure and the information structure they face throughout the session, via both the instructions and computer screen displays. Each period, participants were allowed to choose from four feasible decision rules:

- Continue always, regardless of your clue $(R A)$;

- Withdraw if your clue is low, otherwise continue $(F L)$;

- Withdraw if your clue is low or medium, otherwise continue $(F M)$;

- Withdraw always, regardless of your clue $(F A)$.

Each period each participant submits a decision rule to the experimenter prior to receiving his/her clue $^{3}$ for that period. Each participant sees his or her decision rule executed ten rounds then receives a new clue and resubmits a decision rule. Each time a decision is executed the participant sees only his or her own clue and action, and whether the project succeeded or failed. Participants are never informed about the true state, or the distribution of decisions in their eight-person groups. So a participant with the medium signal can never be certain whether a project outcome occurred because of the state of nature or the actions of others. ${ }^{4}$ Each session is terminated without warning after ten decision rules are submitted and executed over ten rounds.

randomly assigned seven other responders for the purpose of determining project outcome and their payoffs. The difference between a group member and an alternate is that the decisions of the alternates did not affect project outcomes of any group. This method yielded three groups and zero alternates in four sessions and two groups with five alternates in two sessions.

${ }^{3}$ The experiment uses the word "clue" to denote a participant's private signal, and the words, "continue" and "withdraw" for roll over and foreclose, respectively.

${ }^{4}$ This level of incomplete information helps maintain a barrier to tacit communication among participants. 


\section{Results}

Tables 4 and 5 show the frequency with which each decision rule was the modal choice of each participant.

\section{[TABLES 4 AND 5]}

Table 4 shows the baseline Low transparency settings. In both low transparency settings, players have a dominant strategy and the equilibrium is unique. In the Optimistic setting 23 out of 24 participants chose $\mathrm{Fl}$ (foreclose on the low signal) most frequently. In the Pessimistic setting 19 out of 21 participants chose $F m$ (foreclose on the low or medium signal) most frequently. These results support the Nash equilibrium prediction for each setting.

Table 5 shows the results of the Higher and Highest transparency treatments. In these treatments there are multiple equilibria. The efficient equilibrium is always $F l$; the risk dominant equilibrium varies with the level of transparency and with the level of prior optimism or pessimism. Panel A of Table 4 shows 20 out of 24 participants in the Optimistic, Higher transparency treatment played the risk-dominant, but inefficient, equilibrium $(F m)$ most frequently and only 4 played the efficient equilibrium $(F l)$ most frequently. Also in Panel A, 20.5 out of 24 participants in the Pessimistic, Higher transparency treatment played the risk-dominant and efficient equilibrium $(F l)$ most frequently. Panel B shows the same pattern for the Highest transparency, Optimistic and Pessimistic settings. In the Optimistic, Highest transparency treatment, 19 out of 21 participants most frequently played the risk-dominant equilibrium $(F l)$, while 17 out of 24 participants in the Pessimistic, Highest transparency treatment most frequently chose the risk-dominant, but inefficient, equilibrium $(F m)$.

Table 6 breaks down participants' decision rule choices by period. Panel A compares transparency treatments within the Optimistic setting. Panel B shows the same statistics for the Pessimistic setting. Figures 1 through 6 present these data as histograms, showing the number of participants selecting each decision rule, by period, in each of the six cells of the experiment.

\section{[TABLE 6]}




\section{[Figures 1 - 6]}

In each case, it appears that the risk-dominant decision rule emerges strongly. Of particular interest is the observation that in all treatments that have multiple equilibria the efficient equilibrium $(F l)$ is the most frequently selected in the first period. This might indicate that participants are aware that $\mathrm{Fl}$ gives the highest expected payoff if all players coordinate on that equilibrium. But that choice, and therefore coordination on the efficient equilibrium, is unsustainable when it is not the risk dominant equilibrium.

Table 7 presents summary statistics on the payoff to each strategy. Panel A shows payoffs in the Optimistic setting. Panel B shows them in the Pessimistic setting. Panel C summarizes average total payoffs for participants in all treatments.

\section{[TABLE 7]}

Panels A and B of Table 7 show that ex post, the risk-dominant decision rule had the highest payoff of any strategy across treatments.

\section{DISCUSSION AND CONCLUSION}

In this experiment we study a large group's ability to coordinate on an efficient strategy under different levels of transparency of private information. One clear outcome of this study is that greater transparency of information can lead to more coordination failure. Consider the results in the

Pessimistic economy. When transparency is increased from Low to Higher, most players switch from playing the $F m$ strategy to playing the $F l$ strategy, moving toward greater coordination. But, when transparency is increased additionally to Highest, players tend to switch from $\mathrm{Fl}$ to $\mathrm{Fm}$, decreasing coordination. On the other hand, in the Optimistic economy, an increase in transparency from Higher to Highest caused an increase in the propensity to coordinate, as indicated by the switch from $\mathrm{Fm}$ to $F l$. In all cells, play converged to the risk-dominant equilibrium. Thus, our results indicate that an increase in transparency improves coordination only if it makes the coordination strategy risk dominant. But, if increases in transparency switch the risk dominant-strategy from coordination to 
no-coordination then such increases in transparency damages economic efficiency. In all experimental cells the efficient choice appears strong in early rounds, but it cannot be sustained if it is not risk dominant.

The findings of this experiment have implications for a wide variety of situations where group success depends on the maintained confidence of all participants. Firms that are relying increasingly on virtual teams might find that research and development projects stagnate more easily when decentralized, because of the prevalence of informal local information. Risk dominance would imply management should seek out ways to raise confidence in the commitment level of team members by increasing the expected cost of holding back resources. Firms also commonly make use of public information, focusing on presenting a strong sense of "top management buy-in" that can help to establish optimistic priors on the success of a project. Our study does not offer an explicit remedy for coordination failure, but indicates that an increase in the transparency of information will not always work. The interaction between transparency and risk dominance is crucial. 


\section{REFERENCES}

Anctil, R. M., J. Dickhaut, C. Kanodia, and B. Shapiro. 2004. Information transparency and coordination failure: theory and experiment. Journal of Accounting Research 42 (supplement): 159196.

Carlsson, H. and E. van Damme. 1993. Global games and equilibrium selection. Econometrica, 61(5), 989-1018.

Cooper, R. W., DeJong, D. V., Forsythe, R., and T. W. Ross. 1990. Selection criteria in coordination games: Some experimental results. American Economic Review, 80 (1): 218-233.

Diamond, D. and P. Dybvig, P. 1983. Bank runs, deposit insurance, and liquidity. Journal of Political Economy, 91 (3): 401-419.

Goldstein, I. and A. Pauzner. 2005. Demand-Deposit Contracts and the Probability of Bank Runs. Journal of Finance, 60 (3), 1293-1327.

Harsanyi, J. C. , and R. Selten. 1988. A General Theory of Equilibrium Selection in Games. Massachusetts Institute of Technology Press.

Heinemann, F., R. Nagel, and P. Ockenfels. 2004. Theory of global games on test: experimental analysis of coordination games with public and private information. Econometrica, 72 (5): 15831599.

Hellwig, C. 2002. Public information, private information, and the multiplicity of equilibria in coordination games. Journal of Economic Theory, 107 (2): 191-222.

Morris, S. and H. S. Shin. 1998. Unique Equilibrium in a Model of Self-Fulfilling Currency Attacks. American Economic Review, 88, 587-597.

Morris, S. and H. S. Shin. 2003. Global Games: Theory and Applications, in Advances in Economics and Econometrics, the Eighth World Congress (edited by M. Dewatripont, L. Hansen and S. Turnovsky), Cambridge University Press.

Morris, S. and H. S. Shin. 2004. Coordination risk and the price of debt. European Economic Review, 48, 133 - 153

Van Huyck, J. B., Battalio, R. C., and R. O. Beil. 1990. Tacit coordination games, strategic uncertainty, and coordination failure. American Economic Review, 80 (1): 234-249.

Van Huyck, J. B., Battalio, R. C., and R. O. Beil. 1991. Strategic uncertainty, equilibrium selection, and coordination failure in average opinion games. The Quarterly Journal of Economics, 106 (3): 885-910. 
Table 2

Signal Distributions, Economic Settings, and Predictions

Panel A: Signal distribution in the optimistic setting for Low, Higher, and Highest levels of transparency.

Optimistic Setting: $\pi_{\mathrm{B}}=0.3, \pi_{\mathrm{U}}=0.2, \pi_{\mathrm{S}}=0.5 ; \mathrm{R}=\$ .50, \lambda=\$ 0.20$

\begin{tabular}{|l|l|l|l|l|l|l|l|l|l|}
\hline & \multicolumn{3}{|l}{ Low Transparency } & \multicolumn{3}{l|}{ Higher Transparency } & \multicolumn{2}{l|}{ Highest Transparency } \\
\hline & $\left\{r_{B}, r_{S}\right\}=\{0.4,0.4\}$ & $\multicolumn{2}{l}{r_{B}, r_{S}}=\{0.4,0.9\}$ & $\multicolumn{2}{|l|}{r_{B}, r_{S}}=\{0.9,0.9\}$ \\
\hline State & $B$ & $U$ & $S$ & $B$ & $U$ & $S$ & $B$ & $U$ & $S$ \\
\hline Prob $(l \mid$ State $)$ & 0.4 & 0.0 & 0.0 & 0.4 & 0.0 & 0.0 & 0.9 & 0.0 & 0.0 \\
\hline Prob $(m \mid$ State $)$ & 0.6 & 1.0 & .06 & 0.6 & 1.0 & 0.1 & 0.1 & 1.0 & 0.1 \\
\hline Prob $(h \mid$ State $)$ & 0.0 & 0.0 & 0.4 & 0.0 & 0.0 & 0.9 & 0.0 & 0.0 & 0.9 \\
\hline
\end{tabular}

Panel B: Signal distribution in the pessimistic setting for Low, Higher, and Highest levels of transparency.

Pessimistic Setting: $\pi_{\mathrm{B}}=0.5, \pi_{\mathrm{U}}=0.2, \pi_{\mathrm{S}}=0.3 ; \mathrm{R}=\$ 0.50, \lambda=\$ 0.30$

\begin{tabular}{|l|l|l|l|l|l|l|l|l|l|}
\hline & \multicolumn{3}{l}{ Low Transparency } & \multicolumn{3}{l|}{ Higher Transparency } & \multicolumn{2}{l|}{ Highest Transparency } \\
\hline & $\left\{r_{B}, r_{S}\right\}=\{0.4,0.4\}$ & $\multicolumn{2}{l}{r_{B}, r_{S}}=\{0.9,0.4\}$ & $\multicolumn{2}{|l|}{r_{B}, r_{S}}=\{0.9,0.9\}$ \\
\hline State & $B$ & $U$ & $S$ & $B$ & $U$ & $S$ & $B$ & $U$ & $S$ \\
\hline Prob $(l \mid$ State $)$ & 0.4 & 0.0 & 0.0 & 0.9 & 0.0 & 0.0 & 0.9 & 0.0 & 0.0 \\
\hline Prob $(m \mid$ State $)$ & 0.6 & 1.0 & .06 & 0.1 & 1.0 & 0.6 & 0.1 & 1.0 & 0.1 \\
\hline Prob $(h \mid$ State $)$ & 0.0 & 0.0 & 0.4 & 0.0 & 0.0 & 0.4 & 0.0 & 0.0 & 0.9 \\
\hline
\end{tabular}

States:

$B$ (Bankrupt): Project fails.

$U$ (Uncertain): Projects succeeds if at lease 5 of 8 creditors roll over; otherwise it fails.

$S$ (Solvent): Project succeeds.

Payoffs:

$R$ : success payoff

$\lambda$ : foreclosure payoff

Signals:

$l$ : Low signal

$m$ : Medium signal

$h$ : High signal

Transparency Parameters:

$r_{B}$ : Probability of signal $l$ in state $B$.

$r_{S}$ : Probability of signal $h$ in state $S$. 
Table 3

Signal Distributions, Economic Settings, and Predictions

Panel A: Equilibrium predictions in the optimistic setting for each transparency treatment, expected payoff per decision, opportunity cost of selecting $F m(F I)$ when all others play $F I(F m)$.

Optimistic Setting: $\pi_{B}=0.3, \pi_{U}=0.2, \pi_{S}=0.5 ; R=\$ .50, \lambda=\$ 0.20$

\begin{tabular}{|c|c|c|c|c|}
\hline Transparency & $\begin{array}{c}\text { Equilibrium } \\
\text { Trigger } \\
\text { Strategy }\end{array}$ & $\begin{array}{c}\text { Expected } \\
\text { Payoff Per } \\
\text { Decision }\end{array}$ & $\begin{array}{c}\text { Incremental } \\
\text { Payoff per } \\
\text { Decision for } \\
\text { Defecting to Fm } \\
\text { When All Others } \\
\text { Play Fl }\end{array}$ & $\begin{array}{c}\text { Incremental } \\
\text { Payoff per } \\
\text { Decision for } \\
\text { Defecting to Fl } \\
\text { When All Others } \\
\text { Play Fm }\end{array}$ \\
\hline $\begin{array}{l}\text { Low: } \\
\left\{r_{B}, r_{S}\right\}=\{0.4,0.4\}\end{array}$ & $F l$ & $\$ 3.70$ & $-\$ 0.11$ & $\$ 0.10$ \\
\hline \multirow{2}{*}{$\begin{array}{l}\text { Higher: } \\
\left\{r_{B}, r_{S}\right\}=\{0.4,0.9\}\end{array}$} & $F l$ & $\$ 3.70$ & \multirow[t]{2}{*}{$-\$ 0.40$} & \multirow[t]{2}{*}{$-\$ 0.60$} \\
\hline & $F m^{*}$ & $\$ 3.40$ & & \\
\hline \multirow{2}{*}{$\begin{array}{l}\text { Highest: } \\
\left\{r_{B}, r_{S}\right\}=\{0.9,0.9\}\end{array}$} & $F l^{*}$ & $\$ 4.00$ & \multirow{2}{*}{$-\$ 0.70$} & \multirow{2}{*}{$-\$ 0.30$} \\
\hline & $F m$ & $\$ 3.40$ & & \\
\hline
\end{tabular}

*: Risk-dominant equilibrium

Panel B: Equilibrium predictions in the pessimistic setting for each transparency treatment, expected payoff per decision, opportunity cost of selecting $F m(F l)$ when all others play $F l(F m)$.

Pessimistic Setting: $\pi_{B}=0.5, \pi_{U}=0.2, \pi_{S}=0.3 ; R=\$ 0.50, \lambda=\$ 0.30$

\begin{tabular}{|c|c|c|c|c|}
\hline Transparency & $\begin{array}{c}\text { Equilibrium } \\
\text { Trigger } \\
\text { Strategy }\end{array}$ & $\begin{array}{l}\text { Expected } \\
\text { Payoff Per } \\
\text { Decision }\end{array}$ & $\begin{array}{c}\text { Incremental } \\
\text { Payoff per } \\
\text { Decision for } \\
\text { Defecting to Fm } \\
\text { When All Others } \\
\text { Play Fl }\end{array}$ & $\begin{array}{c}\text { Incremental } \\
\text { Payoff per } \\
\text { Decision for } \\
\text { Defecting to Fl } \\
\text { When All Others } \\
\text { Play Fm }\end{array}$ \\
\hline $\begin{array}{l}\text { Low: } \\
\left\{r_{B}, r_{S}\right\}=\{0.4,0.4\}\end{array}$ & $F m$ & $\$ 3.20$ & $\$ 0.10$ & $-\$ 0.11$ \\
\hline \multirow{2}{*}{$\begin{array}{l}\text { Higher: } \\
\left\{r_{B}, r_{S}\right\}=\{0.9,04\}\end{array}$} & $F l^{*}$ & $\$ 3.90$ & \multirow[t]{2}{*}{$-\$ 0.60$} & \multirow[t]{2}{*}{$-\$ 0.40$} \\
\hline & $F m$ & $\$ 3.20$ & & \\
\hline \multirow{2}{*}{$\begin{array}{l}\text { Highest: } \\
\left\{r_{B}, r_{S}\right\}=\{0.9,0.9\}\end{array}$} & $F l$ & $\$ 3.90$ & \multirow{2}{*}{$-\$ 0.30$} & \multirow{2}{*}{$-\$ 0.70$} \\
\hline & $F m^{*}$ & $\$ 3.50$ & & \\
\hline
\end{tabular}

*: Risk-dominant equilibrium 
Table 4. Number of Participants Who Most Frequently Chose Each Decision Rule in the Low Transparency Settings.

\begin{tabular}{|c|c|c|}
\hline & $\begin{array}{l}\text { Low Transparency } \\
\text { Optimistic setting } \\
\text { (Foreclose if receive Low } \\
\text { Signal (FI) is Bayesian Nash) }\end{array}$ & $\begin{array}{l}\text { Low Transparency } \\
\text { Pessimistic setting } \\
\text { (Foreclose if receive Medium } \\
\text { Signal (Fm) is Bayesian Nash) }\end{array}$ \\
\hline Roll over always (RA) & 1 & 0 \\
\hline $\begin{array}{c}\text { Foreclose if receive } \\
\text { Low Signal (Fl) }\end{array}$ & 23 & 2 \\
\hline $\begin{array}{c}\text { Foreclose if Receive Low or } \\
\text { Medium Signal (Fm) }\end{array}$ & 0 & 19 \\
\hline Foreclose Always (FA) & 0 & 0 \\
\hline
\end{tabular}

In the Optimistic setting, the prior probabilities $(\pi)$ for the three states of nature are as follows: Bankrupt $\left(\pi_{B}=.30\right)$, Uncertain $\left(\pi_{U}=.20\right)$, and Solvent $\left(\pi_{S}=.50\right)$. In the Pessimistic setting, the prior probabilities $(\pi)$ for the three states of nature are as follows: Bankrupt $\left(\pi_{B}=.50\right)$, Uncertain $\left(\pi_{U}=\right.$ $.20)$, and Solvent $\left(\pi_{S}=.30\right)$. The Low Transparency Optimistic setting had 24 participants. The Low Transparency Pessimistic setting had 21 participants. If a participant chose more than one strategy with equal frequency, half a point is given to each decision rule. 
Table 5. Number of Participants Who Most Frequently Chose Each Decision Rule in Higher Transparency and Highest Transparency Settings

Panel A. Higher Transparency Optimistic and Higher Transparency Pessimistic Settings.

\begin{tabular}{|c|c|c|}
\hline & $\begin{array}{l}\text { Higher Transparency } \\
\text { Optimistic setting (Foreclose } \\
\text { if receive Medium Signal } \\
(\text { Fm) is the Risk-Dominant } \\
\text { decision rule) }\end{array}$ & $\begin{array}{l}\text { Higher Transparency } \\
\text { Pessimistic setting (Foreclose if } \\
\text { receive Low Signal (Fl) is the } \\
\text { Risk-Dominant decision rule) }\end{array}$ \\
\hline Decision Rule & 0 & 0 \\
\hline $\begin{array}{c}\text { Foll over always }(R A) \\
\text { Low Signal }(F l)\end{array}$ & 4 & 20.5 \\
\hline $\begin{array}{c}\text { Foreclose if Receive Low } \\
\text { or Medium Signal }(F m)\end{array}$ & 20 & 2.5 \\
\hline Foreclose Always $(F A)$ & 0 & 1 \\
\hline
\end{tabular}

Panel B. Highest Transparency Optimistic and Highest Transparency Pessimistic Settings.

\begin{tabular}{|c|l|l|}
\hline & $\begin{array}{l}\text { Highest Transparency } \\
\text { Optimistic setting (Foreclose } \\
\text { if receive Low Signal (FI) is } \\
\text { the Risk-Dominant decision } \\
\text { rule) }\end{array}$ & $\begin{array}{l}\text { Highest Transparency } \\
\text { Pessimistic setting (Foreclose if } \\
\text { receive Medium Signal (Fm) is } \\
\text { the Risk-Dominant decision } \\
\text { rule) }\end{array}$ \\
\hline Roll over always $(R A)$ & 0 & 0 \\
\hline $\begin{array}{c}\text { Foreclose if receive } \\
\text { Low Signal }(F l)\end{array}$ & 19 & 7 \\
\hline $\begin{array}{c}\text { Foreclose if Receive Low } \\
\text { or Medium Signal }(F m)\end{array}$ & 0 & 17 \\
\hline Foreclose Always $(F A)$ & 0 & 0 \\
\hline
\end{tabular}

In the Optimistic setting, the prior probabilities $(\pi)$ for the three states of nature are as follows: Bankrupt $\left(\pi_{B}=.30\right)$, Uncertain $\left(\pi_{U}=.20\right)$, and Solvent $\left(\pi_{S}=.50\right)$. In the Pessimistic setting, the prior probabilities $(\pi)$ for the three states of nature are as follows: Bankrupt $\left(\pi_{B}=.50\right)$, Uncertain $\left(\pi_{U}=\right.$ $.20)$, and Solvent $\left(\pi_{S}=.30\right)$. Both the Higher Transparency Optimistic and Pessimistic settings had 24 participants. The Highest Transparency Optimistic setting had 21 participants, two of whom did not respond after set three. The Highest Transparency Pessimistic setting had 24 participants. If a participant chose more than one strategy with equal frequency, half a point is given to each decision rule. 
Table 6. Selected Decision Rules by Decision Period

Panel A. Number of Participants Selecting Each Decision Rule by Decision Period in the Optimistic Settings

\begin{tabular}{|c|c|c|c|c|c|c|c|c|c|c|c|c|}
\hline & \multicolumn{4}{|c|}{$\begin{array}{l}\text { Low Transparency Optimistic } \\
\text { (n= } 24 \text { per decision period) } \\
\text { Prediction: } F I\end{array}$} & \multicolumn{4}{|c|}{$\begin{array}{l}\text { Higher Transparency Optimistic } \\
\text { (n= } 24 \text { per decision period) } \\
\text { Prediction: } \text { Fm }\end{array}$} & \multicolumn{4}{|c|}{$\begin{array}{l}\text { Highest Transparency Optimistic } \\
\text { (n= } 21 \text { per decision period) } \\
\text { Prediction: } F I\end{array}$} \\
\hline & $\begin{array}{c}\text { Continu } \\
\mathrm{e} \\
\text { Always } \\
(R A)\end{array}$ & $\begin{array}{c}\text { Foreclos } \\
\text { e } \\
\text { if Low } \\
\text { Signal } \\
(F l)\end{array}$ & $\begin{array}{c}\text { Foreclos } \\
\text { e } \\
\text { If Low } \\
\text { or } \\
\text { Medium } \\
\text { Signal } \\
(F m) \\
\end{array}$ & $\begin{array}{c}\text { Foreclos } \\
\mathrm{e} \\
\text { Always } \\
(F A)\end{array}$ & $\begin{array}{c}\text { Continu } \\
\mathrm{e} \\
\text { Always } \\
(R A)\end{array}$ & $\begin{array}{c}\text { Foreclos } \\
\text { e } \\
\text { if Low } \\
\text { Signal } \\
(F l)\end{array}$ & $\begin{array}{c}\text { Foreclos } \\
\text { e } \\
\text { If Low } \\
\text { or } \\
\text { Medium } \\
\text { Signal } \\
(F m) \\
\end{array}$ & $\begin{array}{c}\text { Foreclos } \\
\mathrm{e} \\
\text { Always } \\
(F A)\end{array}$ & $\begin{array}{c}\text { Continu } \\
\mathrm{e} \\
\text { Always } \\
(R A)\end{array}$ & $\begin{array}{c}\text { Foreclos } \\
\text { e } \\
\text { if Low } \\
\text { Signal } \\
(F l)\end{array}$ & $\begin{array}{c}\text { Foreclos } \\
\mathrm{e} \\
\text { If Low } \\
\text { or } \\
\text { Medium } \\
\text { Signal } \\
(F m) \\
\end{array}$ & $\begin{array}{c}\text { Foreclos } \\
\mathrm{e} \\
\text { Always } \\
(F A)\end{array}$ \\
\hline 1 & 3 & 15 & 6 & 0 & 1 & 12 & 11 & 0 & 0 & 17 & 3 & 0 \\
\hline 2 & 1 & 18 & 5 & 0 & 1 & 10 & 13 & 0 & 0 & 17 & 4 & 0 \\
\hline 3 & 3 & 20 & 1 & 0 & 0 & 9 & 15 & 0 & 1 & 19 & 1 & 0 \\
\hline 4 & 0 & 23 & 1 & 0 & 0 & 7 & 17 & 0 & 2 & 17 & 0 & 0 \\
\hline 5 & 2 & 21 & 1 & 0 & 0 & 6 & 18 & 0 & 0 & 19 & 0 & 0 \\
\hline 6 & 1 & 21 & 2 & 0 & 1 & 4 & 19 & 0 & 1 & 18 & 0 & 0 \\
\hline 7 & 0 & 23 & 1 & 0 & 1 & 5 & 18 & 0 & 1 & 17 & 1 & 0 \\
\hline 8 & 2 & 21 & 1 & 0 & 0 & 4 & 20 & 0 & 0 & 19 & 0 & 0 \\
\hline 9 & 0 & 23 & 0 & 1 & 1 & 0 & 23 & 0 & 0 & 19 & 0 & 0 \\
\hline 10 & 0 & 24 & 0 & 0 & 1 & 3 & 20 & 0 & 1 & 18 & 0 & 0 \\
\hline $\begin{array}{l}\text { Tota } \\
1\end{array}$ & 12 & 209 & 18 & 1 & 6 & 60 & 174 & 0 & 6 & 180 & 9 & 0 \\
\hline
\end{tabular}

In the Optimistic setting, the prior probabilities $(\pi)$ for the three states of nature are as follows: Bankrupt $\left(\pi_{B}=.30\right)$, Uncertain $\left(\pi_{U}=.20\right)$, and Solvent $\left(\pi_{S}=.50\right)$. The Highest Transparency Optimistic setting had 21 participants, however, one participant did not respond in set one and two participants did not respond in sets four through ten. 


\section{Table 6 (Continued)}

Panel B. Number of Participants Selecting Each Decision Rule by Decision Period in the Pessimistic Settings

\begin{tabular}{|c|c|c|c|c|c|c|c|c|c|c|c|c|}
\hline & \multicolumn{4}{|c|}{$\begin{array}{l}\text { Low Transparency Pessimistic } \\
\text { (n= } 21 \text { per decision period) } \\
\text { Prediction: } F m\end{array}$} & \multicolumn{4}{|c|}{$\begin{array}{l}\text { Higher Transparency Pessimistic } \\
\text { (n= } 24 \text { per decision period) } \\
\text { Prediction: } F \mathbf{l}\end{array}$} & \multicolumn{4}{|c|}{$\begin{array}{l}\text { Highest Transparency Pessimistic } \\
\text { (n= } 24 \text { per decision period) } \\
\text { Prediction: } \text { Fm }\end{array}$} \\
\hline & $\begin{array}{l}\text { Continu } \\
\text { e } \\
\text { Always } \\
(R A)\end{array}$ & $\begin{array}{c}\text { Foreclos } \\
\text { e } \\
\text { if Low } \\
\text { Signal } \\
(F l)\end{array}$ & $\begin{array}{c}\text { Foreclos } \\
\text { e } \\
\text { If Low } \\
\text { or } \\
\text { Medium } \\
\text { Signal } \\
(F m)\end{array}$ & $\begin{array}{c}\text { Foreclos } \\
\mathrm{e} \\
\text { Always } \\
(F A)\end{array}$ & $\begin{array}{l}\text { Continu } \\
\mathrm{e} \\
\text { Always } \\
(R A)\end{array}$ & $\begin{array}{c}\text { Foreclos } \\
\text { e } \\
\text { if Low } \\
\text { Signal } \\
(F l)\end{array}$ & $\begin{array}{c}\text { Foreclos } \\
\mathrm{e} \\
\text { If Low } \\
\text { or } \\
\text { Medium } \\
\text { Signal } \\
(F m)\end{array}$ & $\begin{array}{c}\text { Foreclos } \\
\text { e } \\
\text { Always } \\
(F A)\end{array}$ & $\begin{array}{l}\text { Continu } \\
\mathrm{e} \\
\text { Always } \\
(R A)\end{array}$ & $\begin{array}{c}\text { Foreclos } \\
\text { e } \\
\text { if Low } \\
\text { Signal } \\
(F l)\end{array}$ & $\begin{array}{c}\text { Foreclos } \\
\text { e } \\
\text { If Low } \\
\text { or } \\
\text { Medium } \\
\text { Signal } \\
(F m)\end{array}$ & $\begin{array}{c}\text { Foreclos } \\
\mathrm{e} \\
\text { Always } \\
(F A)\end{array}$ \\
\hline 1 & 0 & 10 & 11 & 0 & 0 & 14 & 10 & 0 & 0 & 13 & 9 & 1 \\
\hline 2 & 0 & 11 & 10 & 0 & 0 & 12 & 11 & 1 & 0 & 12 & 12 & 0 \\
\hline 3 & 1 & 8 & 12 & 0 & 0 & 15 & 7 & 1 & 1 & 11 & 11 & 1 \\
\hline 4 & 1 & 4 & 15 & 1 & 0 & 19 & 4 & 1 & 0 & 12 & 12 & 0 \\
\hline 5 & 0 & 5 & 16 & 0 & 0 & 20 & 3 & 1 & 0 & 10 & 14 & 0 \\
\hline 6 & 0 & 4 & 17 & 0 & 0 & 19 & 4 & 1 & 0 & 5 & 19 & 0 \\
\hline 7 & 0 & 3 & 18 & 0 & 0 & 19 & 4 & 1 & 0 & 5 & 19 & 0 \\
\hline 8 & 0 & 2 & 19 & 0 & 0 & 22 & 1 & 1 & 0 & 8 & 16 & 0 \\
\hline 9 & 0 & 1 & 20 & 0 & 0 & 22 & 1 & 1 & 0 & 2 & 22 & 0 \\
\hline 10 & 0 & 0 & 21 & 0 & 0 & 22 & 1 & 1 & 0 & 4 & 20 & 0 \\
\hline $\begin{array}{l}\text { Tota } \\
1\end{array}$ & 2 & 48 & 159 & 1 & 0 & 184 & 46 & 9 & 1 & 82 & 154 & 2 \\
\hline
\end{tabular}

In the Pessimistic setting, the prior probabilities $(\pi)$ for the three states of nature are as follows: Bankrupt $\left(\pi_{B}=.50\right)$, Uncertain $\left(\pi_{U}=.20\right)$, and Solvent $\left(\pi_{S}=.30\right)$. The Highest Transparency Pessimistic setting had 24 participants, however, one participant did not respond in set one. 
Table 7. Payoffs

Panel A. Frequency of Payoffs and Mean Payoff per Decision Rule in the Optimistic Settings

\begin{tabular}{|c|c|c|c|c|c|c|c|c|c|c|c|c|}
\hline \multirow[b]{2}{*}{ Decision Rule } & \multicolumn{4}{|c|}{$\begin{array}{l}\text { Low Transparency Payoffs } \\
\text { (n = 2,400 participant rounds) }\end{array}$} & \multicolumn{4}{|c|}{$\begin{array}{l}\text { Higher Transparency } \\
\text { (n = 2,400 participant rounds) }\end{array}$} & \multicolumn{4}{|c|}{$\begin{array}{l}\text { Highest Transparency } \\
\text { (n = 2,100 participant rounds) }\end{array}$} \\
\hline & $\$ 0.00$ & $\$ 0.20$ & $\$ 0.50$ & Mean Pay & $\$ 0.00$ & $\$ 0.20$ & $\$ 0.50$ & $\begin{array}{l}\text { Mean } \\
\text { Pay }\end{array}$ & $\$ 0.00$ & $\$ 0.20$ & $\$ 0.50$ & $\begin{array}{l}\text { Mean } \\
\text { Pay }\end{array}$ \\
\hline Foreclose always $(F A)$ & 0 & 10 & 0 & 0.200 & 0 & 0 & 0 & 0 & 0 & 0 & 0 & 0 \\
\hline $\begin{array}{l}\text { Foreclose if Low or Medium } \\
\text { Signal }(\mathrm{Fm})\end{array}$ & 0 & 156 & 34 & 0.254 & 0 & 997 & 733 & 0.327 & 0 & 66 & 34 & 0.302 \\
\hline Foreclose if Low Signal $(F l)$ & 411 & 295 & 1374 & 0.359 & 231 & 57 & 322 & 0.283 & 48 & 385 & 1357 & 0.422 \\
\hline Roll over always $(R A)$ & 48 & 0 & 72 & 0.300 & 32 & 0 & 28 & 0.233 & 12 & 0 & 48 & 0.400 \\
\hline Non-responding & 0 & 0 & 0 & 0 & 0 & 0 & 0 & 0 & 150 & 0 & 0 & 0 \\
\hline
\end{tabular}

In the Optimistic setting, the prior probabilities $(\pi)$ for the three states of nature are as follows: Bankrupt $\left(\pi_{B}=.30\right)$, Uncertain $\left(\pi_{U}=.20\right)$, and Solvent $\left(\pi_{S}=.50\right)$. 
Table 7 (Continued)

Panel B. Frequency of Payoffs and Mean Payoff per Decision Rule in the Pessimistic Settings

\begin{tabular}{|c|c|c|c|c|c|c|c|c|c|c|c|c|}
\hline \multirow[b]{2}{*}{ Decision Rule } & \multicolumn{4}{|c|}{$\begin{array}{l}\text { Low Transparency Payoffs } \\
\text { (n = 2,100 participant rounds) }\end{array}$} & \multicolumn{4}{|c|}{$\begin{array}{l}\text { Higher Transparency } \\
\text { (n = 2,400 participant rounds) }\end{array}$} & \multicolumn{4}{|c|}{$\begin{array}{l}\text { Highest Transparency } \\
\text { (n = 2,400 participant rounds) }\end{array}$} \\
\hline & $\$ 0.00$ & $\$ 0.30$ & $\$ 0.50$ & Mean Pay & $\$ 0.00$ & $\$ 0.30$ & $\$ 0.50$ & $\begin{array}{l}\text { Mean } \\
\text { Pay }\end{array}$ & $\$ 0.00$ & $\$ 0.30$ & $\$ 0.50$ & $\begin{array}{l}\text { Mean } \\
\text { Pay }\end{array}$ \\
\hline Foreclose always $(F A)$ & 0 & 10 & 0 & 0.300 & 0 & 90 & 0 & 0.300 & 0 & 20 & 0 & 0.300 \\
\hline $\begin{array}{l}\text { Foreclose if Low or Medium } \\
\text { Signal }(F m)\end{array}$ & 0 & 1381 & 209 & 0.326 & 0 & 412 & 48 & 0.320 & 0 & 1044 & 476 & 0.363 \\
\hline Foreclose if Low Signal $(F l)$ & 226 & 82 & 172 & 0.230 & 127 & 849 & 854 & 0.373 & 165 & 296 & 379 & 0.331 \\
\hline Roll over always $(R A)$ & 16 & 0 & 4 & 0.100 & 10 & 0 & 10 & 0.250 & 7 & 0 & 3 & 0.150 \\
\hline Non-responding & 0 & 0 & 0 & 0 & 0 & 0 & 0 & 0 & 10 & 0 & 0 & 0 \\
\hline
\end{tabular}

In the Pessimistic setting, the prior probabilities $(\pi)$ for the three states of nature are as follows: Bankrupt $\left(\pi_{B}=.50\right)$, Uncertain $\left(\pi_{U}=.20\right)$, and Solvent $\left(\pi_{S}=.30\right)$. 


\section{Table 7 (continued)}

\section{Panel C. Total Payoff Per Participant, Excluding \$10 Show-Up Fee}

\begin{tabular}{|c|c|c|c|c|c|c|}
\hline & & $\mathbf{N}$ & Min & Max & Mean & S.D. \\
\hline \multirow{3}{*}{$\begin{array}{l}\text { Optimistic } \\
\text { Settings }\end{array}$} & Low Transparency & 24 & $\$ 29.50$ & $\$ 36.80$ & $\$ 34.68$ & $\$ 1.87$ \\
\hline & $\begin{array}{l}\text { Higher } \\
\text { Transparency }\end{array}$ & 24 & $\$ 28.20$ & $\$ 33.80$ & $\$ 31.35$ & $\$ 1.29$ \\
\hline & $\begin{array}{l}\text { Highest } \\
\text { Transparency }\end{array}$ & 21 & $\$ 12.20$ & $\$ 42.60$ & $\$ 38.56$ & $\$ 8.90$ \\
\hline \multirow{3}{*}{$\begin{array}{l}\text { Pessimistic } \\
\text { Settings }\end{array}$} & Low Transparency & 21 & $\$ 23.40$ & $\$ 33.00$ & $\$ 30.21$ & $\$ 2.18$ \\
\hline & $\begin{array}{l}\text { Higher } \\
\text { Transparency }\end{array}$ & 24 & $\$ 29.80$ & $\$ 38.90$ & $\$ 35.89$ & $\$ 2.10$ \\
\hline & $\begin{array}{l}\text { Highest } \\
\text { Transparency }\end{array}$ & 24 & $\$ 30.90$ & $\$ 36.80$ & $\$ 34.88$ & $\$ 1.65$ \\
\hline
\end{tabular}

In the Optimistic setting, the prior probabilities $(\pi)$ for the three states of nature are as follows: Bankrupt $\left(\pi_{B}=.30\right)$, Uncertain $\left(\pi_{U}=.20\right)$, and Solvent $\left(\pi_{S}=.50\right)$. In the Pessimistic setting, the prior probabilities $(\pi)$ for the three states of nature are as follows: Bankrupt $\left(\pi_{B}=.50\right)$,

Uncertain $\left(\pi_{U}=.20\right)$, and Solvent $\left(\pi_{S}=.30\right)$. 
Figure 1

Low Transparency Optimistic

Prediction Fl

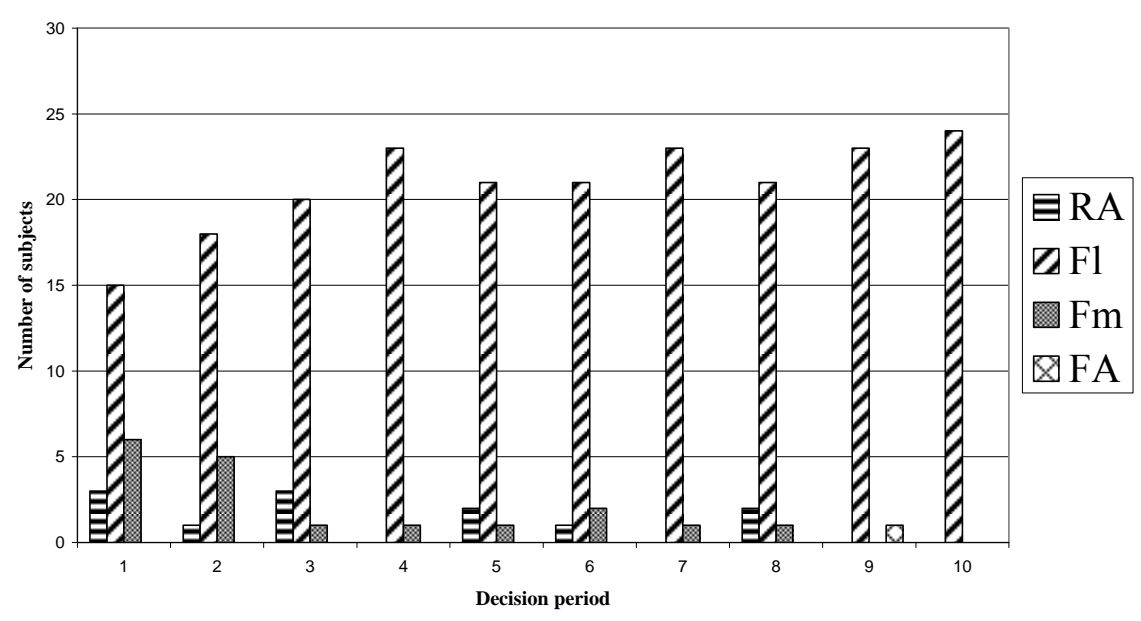

Figure 2

Higher Transparency Optimistic

Prediction Fl or Fm*

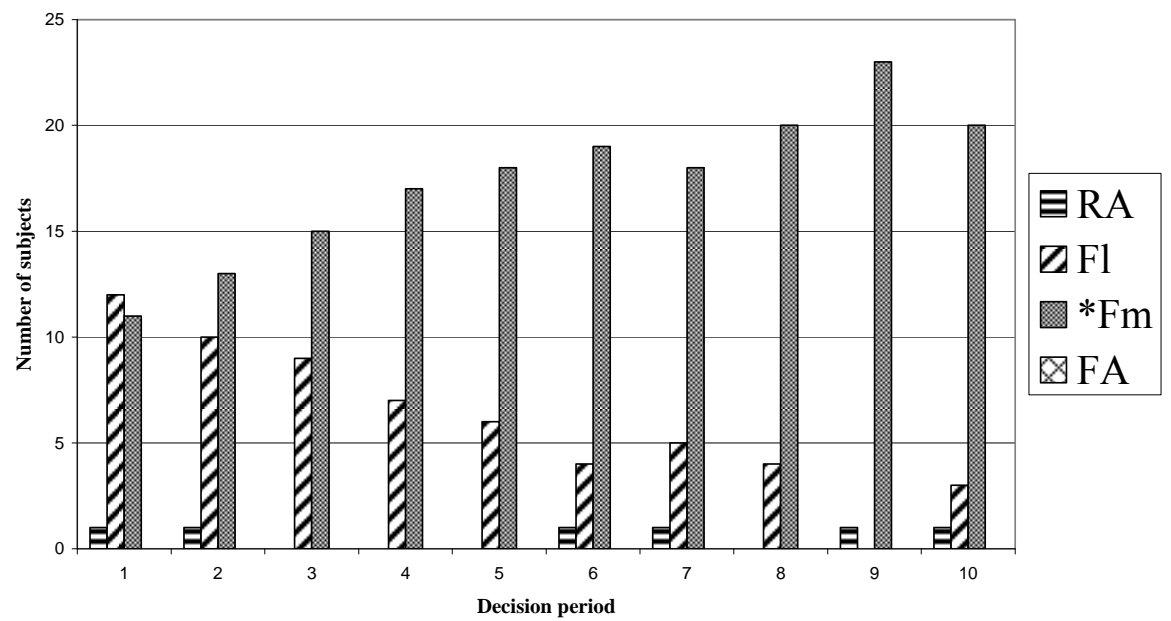

* Risk-dominant equilibrium

Figure 3 
Highest Transparency Optimistic

Prediction Fl* or Fm

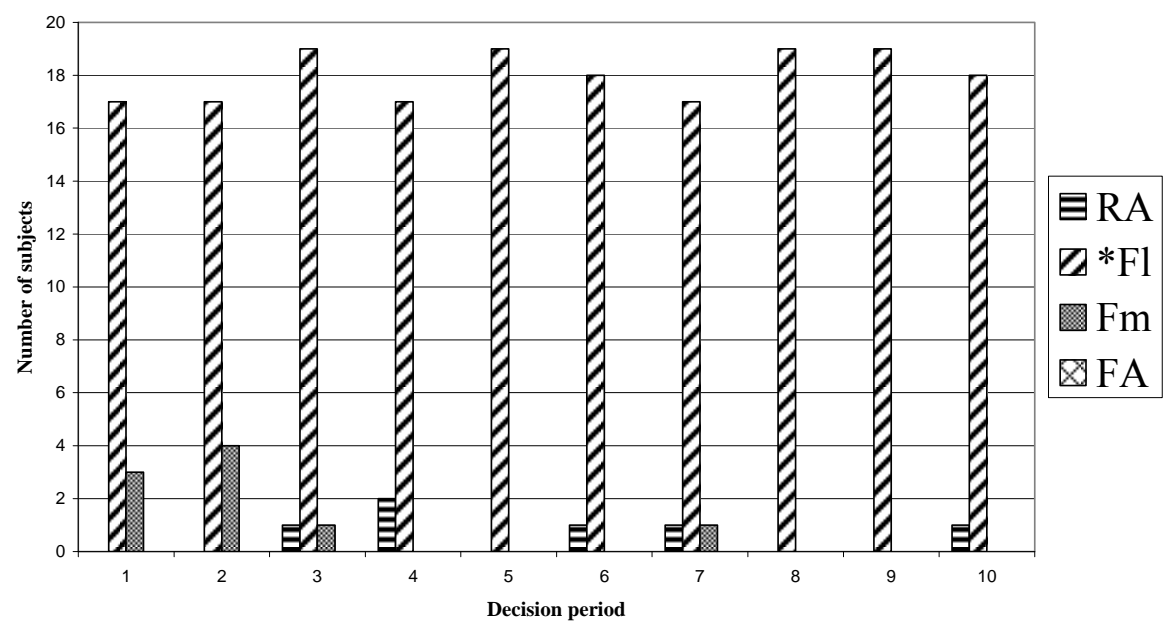

* Risk-dominant equilibrium

Figure 4

Low Transparency Pessimistic

Prediction Fm

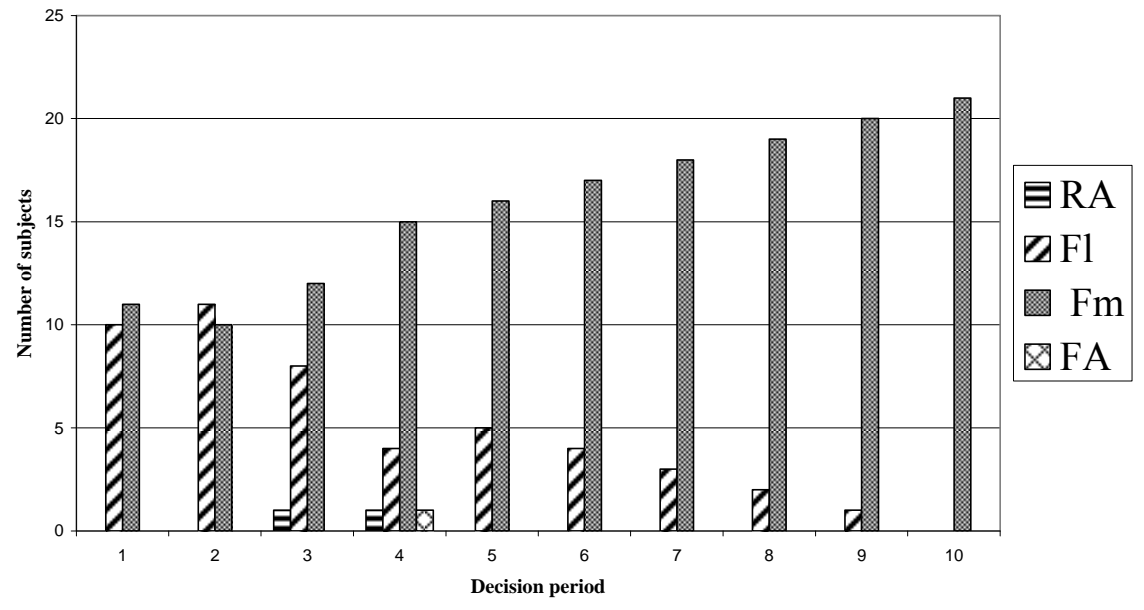

Figure 5 
Higher Transparency Pessimistic

\section{Prediction Fl* or Fm}

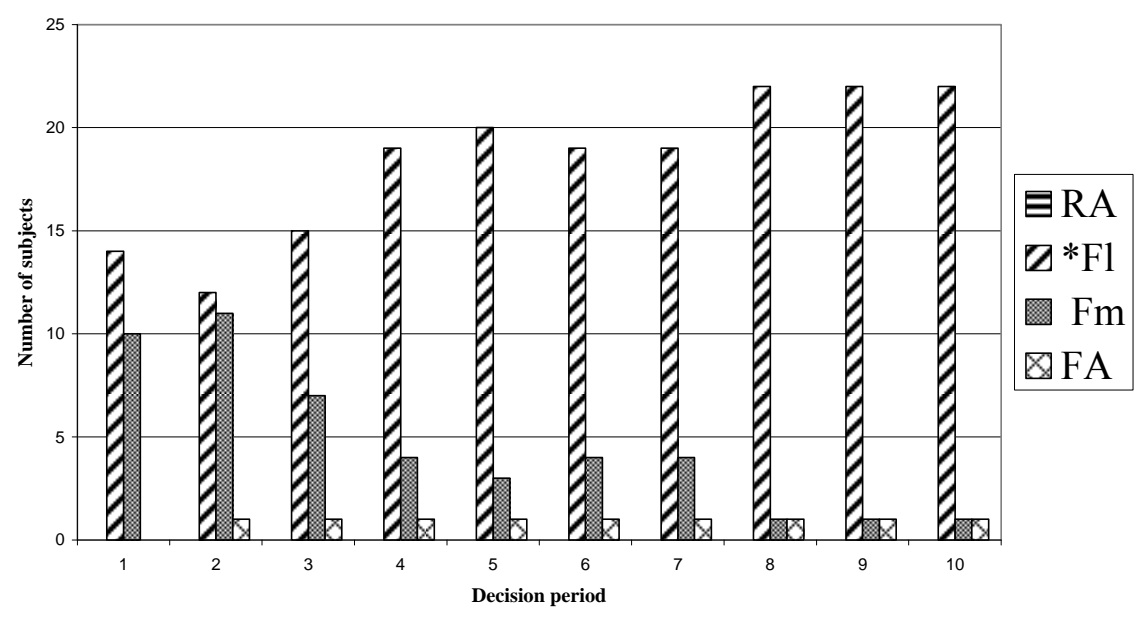

* Risk-dominant equilibrium

Figure 6

Highest Transparency Pessimistic

Prediction Fl or Fm*

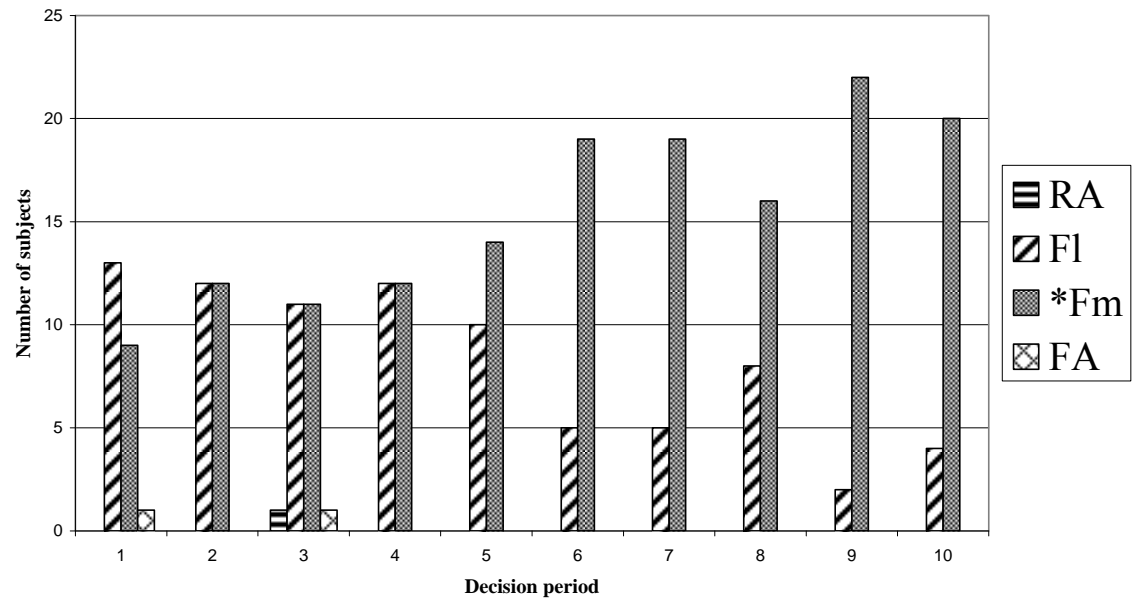

* Risk-dominant equilibrium 


\section{APPENDIX}

ID \#:

\section{Instructions}

Thank you for participating in this experiment. Your identification number is printed at the top of this page.

This experiment is concerned with decision making in a market setting. You are guaranteed to receive $\$ 10$ for showing up on time. By following the instructions carefully and making good decisions, you may earn a considerable amount of money in addition to the $\$ 10$. This additional money will range from approximately $\$ 20$ to $\$ 50$. The actual amount of additional money that you may earn will depend on your decisions and the decisions of other participants. Your money will be paid to you in cash after the experiment ends. You will need to sign and date a compensation receipt form before you receive your payment.

Throughout the experiment, please observe the following rules during the instructions and experiment:

1. Do not talk to any other participant at any time. The screens between the participants are to maintain privacy.

2. You will use your mouse to select decisions during the experiment. Do not use your mouse or keyboard to play around with the software running on your computer. If you unintentionally or intentionally close the software program running on your computer, you will be asked to leave. If this happens, you will receive only your $\$ 10$ fee for showing up.

3. If you have any questions, raise your hand. An experimenter will answer your questions privately.

4. At the end of the instructions, you will take a short quiz to verify that you understand the experimental procedures.

For easy reference, your computer screen will display the tables and figures in these instructions. Right now, your computer screen should be blank. 


\section{Your Role in the Experiment}

Throughout the experiment, you will be randomly grouped with 7 other participants. You and the other participants will each be a creditor to a company to whom you have lent money. The company has borrowed your money in order to fund a project. Each creditor (including you) will decide whether to (1) Continue to invest his or her money in the company until the project is complete, or (2) Withdraw his or her money before the project is complete.

The experiment will consist of multiple sets. Each set has 10 rounds. For example, two sets include a total of 20 rounds, and 40 sets include a total of 400 rounds. You will not know how many sets will be played until the experiment ends.

\section{Your Payoffs}

As shown in Table 1, your payoffs in each round will depend on your decision (Continue or Withdraw) and whether the project succeeds or fails. When you make your decision, you will not know for certain whether the project will succeed or fail. Please take a moment to review Table 1:

Table 1: Payoff Schedule (Per Round)

\begin{tabular}{|l|c|c|}
\hline & Project Succeeds & Project Fails \\
\hline You Continue & $\$ 0.50$ & $\$ 0.00$ \\
\hline You Withdraw & $\$ 0.20$ & $\$ 0.20$ \\
\hline
\end{tabular}

Table 1 appears in the upper left corner of your computer screen.

Below, please write down your answers to the following questions on this page about Table 1. In a few moments the experimenter will review the correct answers with you.

1. If you withdrew your money in an experimental round, how much money would you receive?

2. If you continued to invest your money in an experimental round, what would your payoff depend on? 


\section{Project Success or Failure}

There are three possible states of nature: Solvent, Uncertain, and Bankrupt. Project success is guaranteed when the state of nature is Solvent. Project failure is guaranteed when the state of nature is Bankrupt. When the state of nature is Uncertain, the project succeeds only if at least 5 creditors continue to invest. Only one state of nature will occur in each experimental round. Table 2 shows the percentage of times each state of nature will occur, and the project outcome for each state of nature. Table 2 appears below Table 1 in the upper left corner of your computer screen. Please take a moment to review this table:

Table 2: Percentage of times each state of nature will occur and the project outcome for each state of nature.

\begin{tabular}{|l|c|c|}
\hline State of nature & $\begin{array}{c}\text { Percentage of times each state } \\
\text { of nature will occur }\end{array}$ & Project Outcome \\
\hline Solvent & $50 \%$ & Success is guaranteed \\
\hline Uncertain & $20 \%$ & $\begin{array}{c}\text { Project succeeds if at least } \\
5 \text { out of } 8 \text { creditors } \\
\text { continue to invest }\end{array}$ \\
\hline Bankrupt & $30 \%$ & Failure is guaranteed \\
\hline
\end{tabular}

Table 2 appears below Table 1 in the upper left corner of your computer screen.

Below, please write down your answers to the following questions on this page about Table 2. In a few moments the experimenter will review the correct answers with you.

1. If you were to participate in this experiment for 100 rounds, how many times would you expect
A. the Solvent state of nature to occur?
times
B. the Bankrupt state of nature to occur?
times
C. the Uncertain state of nature to occur? times

2. If the state of nature is Solvent and 4 out of 8 creditors continued to invest their money, what would be the project outcome? (check one:) Success Failure

3. If the state of nature is Bankrupt and 6 out of 8 creditors continued to invest their money, what would be the project outcome? (check one:) Success Failure

4. If the state of nature is Uncertain and 6 out of 8 creditors continued to invest their money, what would be the project outcome? (check one:) Success Failure

5. If the state of nature is Uncertain and 4 out of 8 creditors continued to invest their money, what would be the project outcome? (check one:) Success Failure 


\section{Your Clues about the State of Nature}

Each experimental round, a computer will randomly select one of the three states of nature based on the percentages shown in Table 2. You will not observe which state of nature the computer has selected. Instead, you will observe one of three clues (Low, Medium, or High) about the state of nature. Each creditor will observe only his or her clue. After you receive your clue, you will decide whether to continue to invest or withdraw your money. Figure 1 shows the clues and project outcomes for each state of nature.

Figure 1 appears below and on a separate sheet of paper for your convenient reference. Please follow along as we describe Figure 1:

Figure 1

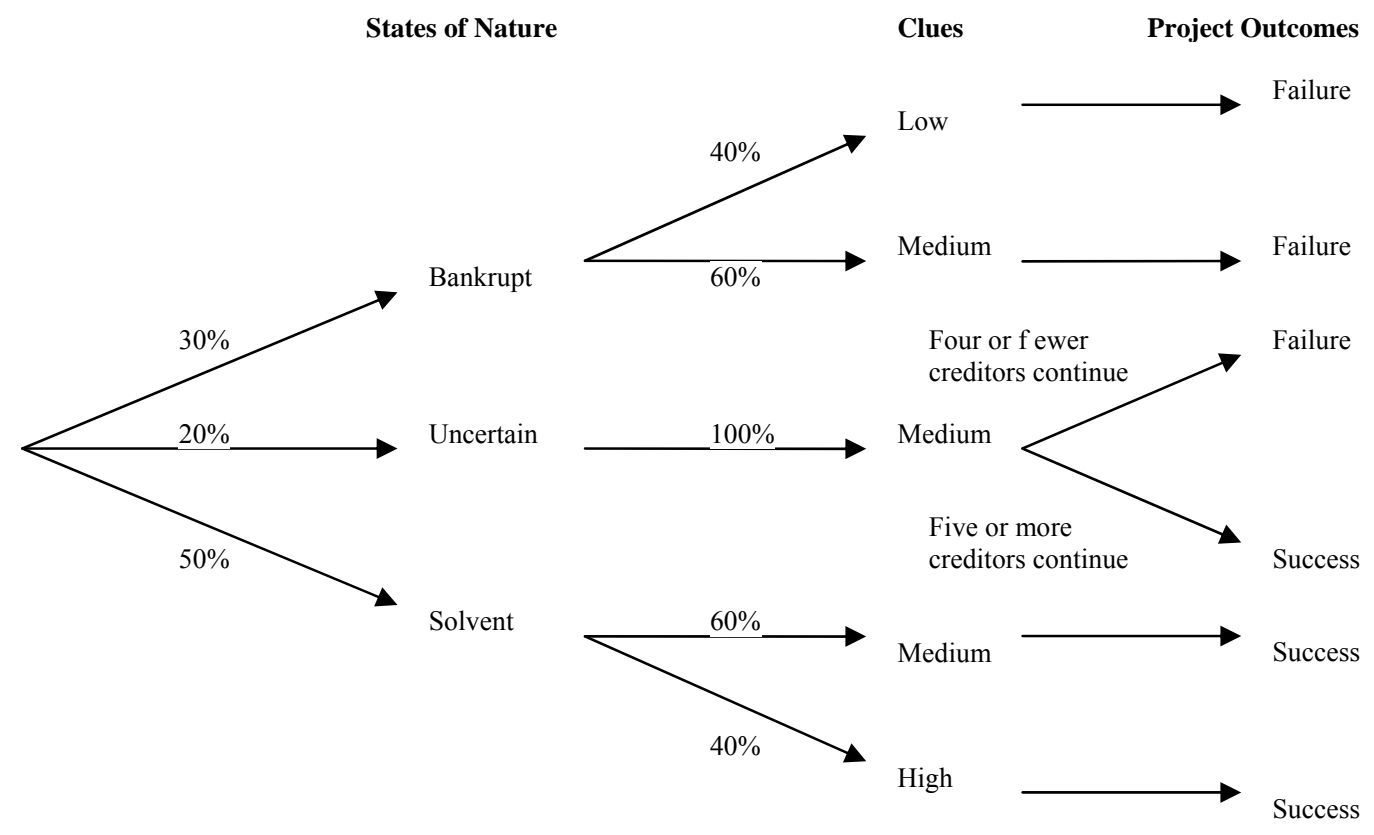


Below, please write down your answers to the following questions on this page about Figure 1. In a few moments the experimenter will review the correct answers with you.

1. If you receive the Low clue, what state of nature occurred?
a. Solvent
b. Uncertain
c. Bankrupt
d. cannot be determined with certainty

2. If you receive the Medium clue, what state of nature occurred?
a. Solvent
b. Uncertain
c. Bankrupt
d. cannot be determined with certainty

3. If you receive the High clue, what state of nature occurred?
a. Solvent
b. Uncertain
c. Bankrupt
d. cannot be determined with certainty

4. If you receive the Low clue,

A. is it possible that others will receive the Medium clue?

Yes

No

B. is it possible that others will receive the High clue?

Yes No

5. If you receive the Medium clue,
A. is it possible that others will receive the Low clue?
B. is it possible that others will receive the High clue?

Yes No Yes __ No

6. If you receive the High clue,
A. is it possible that others will receive the Low clue?
B. is it possible that others will receive the Medium clue?

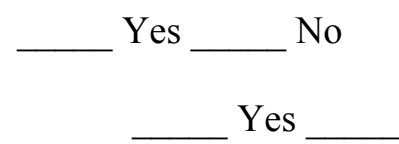

No 


\section{Making Your Decision to Continue or Withdraw}

You will choose a decision rule to indicate your decisions in the experiment. Your decision rule will specify which clues will lead you to continue to invest your money and which clues will lead you to withdraw your money. After you receive your private clue in an experimental round, your decision rule will be executed by the computer. You can choose one of four decision rules:

\section{Decision Rule \\ Select a Decision Rule by Clicking the Appropriate Box \\ $\square$ Continue always, regardless of your clue \\ $\square$ Withdraw if your clue is Low, otherwise continue \\ $\square$ Withdraw if your clue is Low or Medium, otherwise continue \\ $\square$ Withdraw always, regardless of your clue}

The decision rules are displayed in the upper right corner of your computer screen. During the experiment you will indicate your choice by clicking on the appropriate box.

Choose your decision rule carefully because it will remain in effect for 10 experimental rounds. After that, you may revise your decision rule for the next set of 10 rounds, and so on.

\section{How Your Decision Rule Will Be Executed}

Your decision rule will be executed in the following manner for each experimental round:

1. The computer will use the percentages in Table 2 and Figure 1 to generate a state of nature and private clues for each creditor.

2. The computer will compare your private clue with your decision rule to determine whether you continue to invest or withdraw your money for that round.

3. The computer will tabulate how many creditors continue to invest, determine whether the project fails or succeeds, and calculate your payoff for that round.

4. After 10 such rounds, you may revise your decision rule for the next 10 rounds. 
Below, please write down your answers to the following questions on this page about the decision rules. In a few moments the experimenter will review the correct answers with you.

1. For how many experimental rounds will your decision rule apply? rounds

2. Suppose you selected the decision rule which states "Withdraw if your clue is Low, otherwise continue."

A. If you receive the Medium clue, what would your decision be? Continue Withdraw

B. If you receive the Low clue, what would your decision be? Continue __ Withdraw

3. Suppose you selected the decision rule which states "Withdraw if your clue is Low or Medium, otherwise continue."

A. If you receive the Low clue, what would your decision be? Continue Withdraw

B. If you receive the High clue, what would your decision be? Continue Withdraw

C. If you receive the Medium clue, what would your decision be? Continue Withdraw 


\section{Market Activity and Payoff Report}

The middle of your computer screen will report the market activity and payoff information in Table 3. This table will be displayed as shown below. For this example, suppose that you chose the decision rule which states "Withdraw if your clue is Low, otherwise continue" and that Round 4 has just been completed. Please take a few moments to verify that you understand the information in Table 3:

Table 3: Market Activity and Payoff Report

\begin{tabular}{|c|c|l|c|c|}
\hline Round & Your Clue & $\begin{array}{c}\text { Your } \\
\text { Decision }\end{array}$ & $\begin{array}{c}\text { Project } \\
\text { Status }\end{array}$ & $\begin{array}{c}\text { Your } \\
\text { Payoff }\end{array}$ \\
\hline 1 & High & Continue & Success & $\mathbf{\$ 0 . 5 0}$ \\
2 & Low & Withdraw & Failure & $\mathbf{\$ 0 . 2 0}$ \\
3 & Medium & Continue & Failure & $\mathbf{\$ 0 . 0 0}$ \\
4 & Medium & Continue & Success & $\mathbf{\$ 0 . 5 0}$ \\
5 & & & & \\
6 & & & & \\
7 & & & & \\
8 & & & & \\
9 & & & & \\
10 & & & & \\
\hline
\end{tabular}

Table 3 is displayed in the middle of your computer screen and will be updated after each experimental round. 


\section{Set Choices and Payoffs}

After each experimental round, the computer will report your Set Choices and Payoffs in Table 4. This table will appear at the bottom of your computer screen. The table will be displayed as follows:

Table 4: Set Choices and Payoffs

\begin{tabular}{|c|l|l|l|}
\hline Set & \multicolumn{1}{|c|}{$\begin{array}{c}\text { Decision } \\
\text { Rule }\end{array}$} & \multicolumn{1}{|c|}{$\begin{array}{c}\text { Payoff } \\
\text { Per Set }\end{array}$} & $\begin{array}{c}\text { Experiment } \\
\text { Cumulative Payoff }\end{array}$ \\
\hline 1 & $\begin{array}{l}\text { A brief description of } \\
\text { your decision rule will } \\
\text { appear in this column }\end{array}$ & $\begin{array}{l}\text { Your payoffs for the } \\
\text { most recent set will be } \\
\text { updated in this column } \\
\text { after each experimental } \\
\text { round. }\end{array}$ & $\begin{array}{l}\text { Your cumulative } \\
\text { payoff for the } \\
\text { experiment will be } \\
\text { updated in this column } \\
\text { after each } \\
\text { experimental round. }\end{array}$ \\
\hline 2 & & & \\
\hline etc. & & & \\
\hline
\end{tabular}

Table 4 is displayed at the bottom of your computer screen. 


\section{Summary of Experimental Procedures}

The experiment consists of multiple sets of 10 rounds. You will not know how many sets will be played until the experiment ends. Each set of 10 rounds will consist of the following steps:

1. You will be randomly and anonymously grouped with seven other creditors. For each set of 10 rounds you will be grouped with a different set of seven creditors. If the number of creditors exceeds an exact multiple of 8 , the computer will randomly select the remaining creditors to serve as alternates for that set. The computer will randomly select different alternates for each set. Each alternate will be randomly grouped with seven other creditors in order to receive payoffs as fully participating creditors.

2. You will privately select your decision rule for the entire set of 10 rounds.

3. In each of the 10 rounds, the computer will select the state of nature and your private clue. Your investment decision will be executed on your behalf based on your decision rule.

4. For each round, your payoff will be computed based on your investment decision and whether the project succeeded or failed.

5. At the end of each round, you will receive a Market Activity and Payoff Report.

6. Steps $3-5$ will be repeated for each of the 10 rounds in the set.

\section{Limited Time to Make Decisions}

Before the first set of 10 rounds commences, you will have 2 minutes to select a decision rule. For subsequent sets, you will have 1 minute to select a decision rule. You may change your selection any time during this allotted time period. Your computer monitor will display a reminder message thirty seconds before your allotted decision time expires. When the allotted time expires, the computer will execute your decision rule on your behalf for 10 rounds. If you fail to select a decision rule within the allotted time for a particular set, you will not participate in that particular set and your payoff for that set will be $\$ 0.00$.

\section{Conclusion of the Experiment}

At the conclusion of the experiment, an experimenter will ask you to please quietly remain seated. To receive your earnings, you must first hand in your instructions booklet (including the questionnaire on the following pages) and sign a payment receipt form. 
ID \#:

\section{QUESTIONNAIRE ON EXPERIMENTAL PROCEDURES}

The amount of money you will earn in this experiment will depend on how well you understand the market procedures. Please take the following quiz to verify that you understand the procedures. Raise your hand when you are finished. The experiment will begin after each participant completes the quiz.

1. In an experimental round, how much money will you earn if you continue to invest your money in the company and

a. the project succeeds?

$\$$

b. the project fails?

$\$$

2. In an experimental round, how much money will you earn if you withdraw your money from the company and

a. the project succeeds?

$\$$

b. the project fails?

$\$$

3. For an experimental round, when will you find out whether the project actually succeeded or failed?(circle one answer)

a. At the beginning of the experimental round

b. When you receive your private clue about the state of nature in that experimental round.

c. When your decision rule determines whether you will continue or withdraw your money in that experimental round.

d. When the Market Activity and Payoff Report is updated in Table 3 in the middle of your computer screen.

4. Complete the following table, assuming that you chose the decision rule "Withdraw if your clue is Low or Medium, otherwise continue", 6 out of 8 creditors in your group continued to invest, and the state of nature was Uncertain:

Table 3: Market Activity and Payoff Report

\begin{tabular}{|l|c|c|c|c|}
\hline Round & Your Clue & $\begin{array}{c}\text { Your } \\
\text { Decision }\end{array}$ & $\begin{array}{c}\text { Project } \\
\text { Status }\end{array}$ & $\begin{array}{c}\text { Your } \\
\text { Payoff }\end{array}$ \\
\hline
\end{tabular}




\begin{tabular}{|l|l|l|l|l|}
\hline 4 & Medium & & & \\
\hline
\end{tabular}


5. Complete the following table, assuming that you chose the decision rule "Withdraw if your clue is Low, otherwise continue", 4 out of 8 creditors in your group continued to invest, and the state of nature was Uncertain:

Table 3: Market Activity and Payoff Report

\begin{tabular}{|c|c|c|c|c|}
\hline Round & Your Clue & $\begin{array}{c}\text { Your } \\
\text { Decision }\end{array}$ & $\begin{array}{c}\text { Project } \\
\text { Status }\end{array}$ & $\begin{array}{c}\text { Your } \\
\text { Payoff }\end{array}$ \\
\hline 16 & Medium & & & \\
\hline
\end{tabular}

6. Complete the following table, assuming that you chose the decision rule "Withdraw if your clue is Low, otherwise continue", 6 out of 8 creditors in your group continued to invest, and the state of nature was Bankrupt:

Table 3: Market Activity and Payoff Report

\begin{tabular}{|c|c|c|c|c|}
\hline Round & Your Clue & $\begin{array}{c}\text { Your } \\
\text { Decision }\end{array}$ & $\begin{array}{c}\text { Project } \\
\text { Status }\end{array}$ & $\begin{array}{c}\text { Your } \\
\text { Payoff }\end{array}$ \\
\hline 21 & Medium & & & \\
\hline
\end{tabular}

7. Complete the following table, assuming that you chose the decision rule "Withdraw always", 6 out of 8 creditors in your group continued to invest, and the state of nature was Solvent:

Table 3: Market Activity and Payoff Report

\begin{tabular}{|c|c|c|c|c|}
\hline Round & Your Clue & $\begin{array}{c}\text { Your } \\
\text { Decision }\end{array}$ & $\begin{array}{c}\text { Project } \\
\text { Status }\end{array}$ & $\begin{array}{c}\text { Your } \\
\text { Payoff }\end{array}$ \\
\hline 58 & High & & & \\
\hline
\end{tabular}

8. Complete the following table, assuming that you chose the decision rule "Continue always", five creditors continued to invest, and the state of nature was Bankrupt:

Table 3: Market Activity and Payoff Report

\begin{tabular}{|c|c|c|c|c|}
\hline Round & Your Clue & $\begin{array}{c}\text { Your } \\
\text { Decision }\end{array}$ & $\begin{array}{c}\text { Project } \\
\text { Status }\end{array}$ & $\begin{array}{c}\text { Your } \\
\text { Payoff }\end{array}$ \\
\hline 97 & Low & & & \\
\hline
\end{tabular}

AFTER THE EXPERIMENT ENDS, YOU WILL BE ASKED TO HAND IN YOUR INSTRUCTIONS BOOKLET AND THIS QUESTIONNAIRE BEFORE YOU RECEIVE YOUR PAYMENT. 


\section{Economic Science Institute Working Papers}

2008

08-05 Tila, D. and Porter, D. Group Prediction in Information Markets With and Without Trading Information and Price Manipulation Incentives.

08-04 Caginalp, G., Hao, L., Porter, D. and Smith, V. Asset Market Reactions to News: An Experimental Study.

08-03 Thomas, C. and Wilson, B. Horizontal Product Differentiation in Auctions and Multilateral Negotiations.

08-02 Oprea, R., Wilson, B. and Zillante, A. War of Attrition: Evidence from a Laboratory Experiment on Market Exit.

08-01 Oprea, R., Porter, D., Hibbert, C., Hanson, R. and Tila, D. Can Manipulators Mislead Prediction Market Observers? 